\title{
Endoscopic OCT (Presentation Video)
}

\section{Brett Bouma}

Brett E. Bouma, "Endoscopic OCT (Presentation Video)," Proc. SPIE 9312, Optical Coherence Tomography and Coherence Domain Optical Methods in Biomedicine XIX, 93124A (22 April 2015); doi: 10.1117/12.2197216

SPIE. Event: SPIE BiOS, 2015, San Francisco, California, United States 


\title{
Endoscopic OCT \\ (Presentation Video)
}

Brett E. Bouma, Wellman Center for Photomedicine (USA)

\begin{abstract}
In this Hot Topics presentation, Brett Bouma notes how diagnostic procedures using optical coherence tomography (OCT) technology have become the gold standard for detecting diseases of the eye, heart and gastrointestinal tract, looking for disease in the body -- without incisions. Advances in endoscopic OCT have included a 20 -fold increase in image speed, now producing 3,000 frames per second. Other advances include new probes such as tethered capsules, polarization sensitive imaging, and uses in biopsy guidance. The technique has been in use since the 1990s in animals and in humans since 2002. But the clinical community was skeptical until studies in 2003 showed ways to obtain dramatically higher speed imaging of tissues over a wider field of view.
\end{abstract}

View presentation video on SPIE's Digital Library: http://dx.doi.org/10.1117/12.2197216.4093511003001

Optical Coherence Tomography and Coherence Domain Optical Methods in Biomedicine XIX, edited by James G. Fujimoto, Joseph A. Izatt, Valery V. Tuchin, Proc. of SPIE Vol. 9312,

93124A · C 2015 SPIE · CCC code: 1605-7422/15/\$18 - doi: 10.1117/12.2197216 